\title{
Perspectives of dietitians on the taxation of sugar sweetened beverages in South Africa
}

\section{Abstract}

The taxation on sugar sweetened beverages (SSB), known as the health promotion levy (HPL) was implemented in South Africa in April 2018. The aim of the taxation was to reduce the excessive intake of sugar in the SA population. Many studies have linked a high intake of sugar, particularly SSB to an increased energy intake, increasing the risk of overweight and obesity. The aim of this study was to investigate the perspectives of dietitians on the HPL.

Methods: In this cross-sectional descriptive study, dietitians were recruited through the weekly Association of Dietetics in South Africa newsletter and social media platforms. Dietitians $(n=138)$ completed an electronic survey using Survey Monkey. The survey consisted of five sections; consent, demographics, awareness of the sugar taxation, opinions and SSB purchasing/consumption of patients. Descriptive statistics was performed using Statistica version 13.2.

Results: Nearly all of the dietitians were female $(95 \%, \mathrm{n}=131)$, with a mean age of 33 years $( \pm 9.73)$. Two thirds were qualified with a four year professional Honors degree $(67 \%, n=92)$ and $25 \%(n=34)$ had a Master's degree. A majority of dietitians were employed full time $(80 \%, n=111)$, working mainly in the area of clinical nutrition $(26 \%, n=33)$ and private practice $(21 \%, n=27)$. Most dietitians $(98 \%, \mathrm{n}=127)$ were aware of the sugar tax, although $75 \%(\mathrm{n}=98)$ did not know the sugar content where tax was applicable and $78 \%(\mathrm{n}=101)$ did not know the tax amount levied. Dietitians opinion towards the HPL was positive $(75 \%, \mathrm{n}=94)$, although $56 \%(\mathrm{n}=$ 68 ) disagreed it would reduce obesity. A majority of dietitians $(86 \%, n=108)$ indicated other factors contribute to obesity. Most dietitians consult with patients $(73 \%, \mathrm{n}=90)$. Patients were mainly from a lower socio-economic status $(43 \%, \mathrm{n}=60)$. Dietitians disagreed it would reduce their patient's beverage consumption $(61 \%, \mathrm{n}=55)$, with most agreeing the tax was too little to make a difference $(71 \%, \mathrm{n}=89)$ and that it is mainly due to patient's liking the taste for not changing $(46 \%, \mathrm{n}=36)$. Dietitians $(34 \%, \mathrm{n}=$ $31)$ use the SBL as a motivational tool, while $83 \%(n=75)$ teach their patients to look for sugar on food labels.

Conclusion: From the dietitian's perspective, the sugar taxation has not influenced their patient's consumption behaviour. Dietitians have a positive attitude toward the HPL although they don't think it will reduce the prevalence of obesity. Other strategies should be employed to reduce sugar consumption in the SA population.

\section{Conflict of Interest}

There is not conflict of interest 